\title{
The Anxiolytic Effects of Valtrate in Rats Involves Changes of Corticosterone Levels
}

\author{
Shu-Ning Shi, ${ }^{1}$ Jin-Li Shi, ${ }^{1}$ Yong Liu, ${ }^{1}$ Yan-Li Wang, ${ }^{1}$ Chun-Guo Wang, \\ Wen-Hui Hou, ${ }^{1}$ and Jian-You Guo ${ }^{2}$ \\ ${ }^{1}$ School of Chinese Materia Medica, Beijing University of Chinese Medicine, 6A Wangjing Central South Road, Chaoyang District, \\ Beijing 100102, China \\ ${ }^{2}$ Key Laboratory of Mental Health, Institute of Psychology, Chinese Academy of Sciences, 4A Datun Road, Chaoyang District, \\ Beijing 100101, China
}

Correspondence should be addressed to Jin-Li Shi; shij@vip.sina.com and Jian-You Guo; guojy@psych.ac.cn

Received 22 July 2013; Revised 21 November 2013; Accepted 21 November 2013; Published 20 March 2014

Academic Editor: Gerhard Litscher

Copyright (c) 2014 Shu-Ning Shi et al. This is an open access article distributed under the Creative Commons Attribution License, which permits unrestricted use, distribution, and reproduction in any medium, provided the original work is properly cited.

\begin{abstract}
Valtrate is a principle compound isolated from Valeriana jatamansi Jones, which is a Traditional Chinese Medicine used to treat various mood disorders. The aim of the present study was to investigate the anxiolytic effects of valtrate in rats. The animals were orally administered valtrate $(5,10$, and $20 \mathrm{~g} / \mathrm{kg}$ daily) for 10 days and exposed to open field test (OFT) and elevated plus-maze (EPM). Then the corticosterone levels in the rat serum were measured by enzyme-linked immunosorbent assay (ELISA). The valtrate $(10 \mathrm{mg} / \mathrm{kg}$, p.o.) exhibited the anxiolytic effect in rats by increasing the time and entry percentage into the open arms in the EPM and the number of central entries in the OFT. Valtrate $(10 \mathrm{mg} / \mathrm{kg}$, p.o.) significantly reduced the corticosterone level in the rat serum. Taken together, these results suggest that the valtrate has anxiolytic activity in behavioral models that might be mediated via the function of hypothalamus-pituitary-adrenal axis.
\end{abstract}

\section{Introduction}

Anxiety disorder is a common mental illness on society. Millions of people suffer from a mental or behavioral disorder [1]. Previous studies suggest that benzodiazepines are useful first-line agents for most of the anxiety disorders in the world [2]. However, they may produce fearful side effects; for example, long-term use of benzodiazepine can cause cognitive decline in the elderly [3]. In addition, a lot of patients with anxiety disorders fail to adequately respond to existing pharmacologic treatments [4]. Thus, better antianxiety drugs with greater efficacy and fewer side-effects are needed.

Traditional Chinese prescription has been commonly recognized as a safe and effective prescription in the treatment of various mood disorders in China [5]. Valeriana jatamansi Jones was a famous Traditional Chinese Medicine used to treat anxiety disorders in clinical prescription for many years [6]. Recent study has reported that Valeriana jatamansi Jones exerts an anxiolytic effect by improving the frequency and time percentage of the open arm in the elevated plus maze [7]. Chemical researches have shown that it includes essential oils, iridoids, and flavonoids compounds [8], but the anxiolytic active components of Valeriana jatamansi Jones have not been adequately elucidated. Valtrate is a major component of Valeriana jatamansi Jones and has been shown to have antifungal, antitumor, and cytotoxic activities in early studies [9-12]. Currently, valtrate at a high dose has been found to have sedative properties by inhibiting spontaneous motion and increasing the sleeping number induced by pentobarbital sodium in mice [13]. Therefore, these results raises the possibility of the anxiolytic effect of valtrate as the primary antianxiety components in Valeriana jatamansi Jones. However, the anxiolytic effect of valtrate and the mechanism have not been reported.

Therefore, in the present study, we investigated the anxiolytic potential of valtrate isolated from Valeriana jatamansi Jones in rats. The paradigms we selected here to detect the anxiolytic effect of valtrate are two famous tests of anxiety: the open field test (OFT) and the elevated plus maze test (EPM), which have shown good sensitivity to anxiolytic 
drugs. The EPM is a well-established animal model for testing anxiolytic drugs [14] because of its natural stimulus, such as a fear of a new, bright, and open space and the fear of balancing on a relatively narrow raised surface [15]. The OFT has gained popularity as a model of anxiety, which is based on the rodents' natural tendency to stay near the perimeters of a novel environment [16] and the aversion of rodents for open and illuminated spaces [17]. The animals were tested in the OFT and EPM. After the behavior test, we determined whether valtrate altered the serum corticosterone response to stress induced by exposure to the two models.

\section{Material and Methods}

2.1. Animals. 60 male 8-week-old Sprague-Dawley rats (150$170 \mathrm{~g}$ ) were obtained from the Laboratory Animal Center of the Academy of Military Medical Sciences and used for this study. Each animal was housed in individual cages under controlled temperature $\left(22 \pm 1^{\circ} \mathrm{C}\right)$ and a $12 \mathrm{~h} / 12 \mathrm{~h}$ light/dark cycle (lights on at 07:00 AM-19:00 PM) with free access to food and water. The experimenter handled the animals daily to acclimate them to the manipulation. The experimental procedures were approved by the Institutional Animal Care and Use Committee of the Institute of Psychology of the Chinese Academy of Sciences and in accordance with the National Institutes of Health Guide for Care and Use of Laboratory Animals.

2.2. Plant Material and Isolation of Valtrate. Valeriana jatamansi Rhizoma et Radix was purchased from a commercial source in Yunnan province, China. The identity of the herbal medicine was confirmed by Professor Shi Jin-li, a researcher in the Department of Pharmacognosy, Beijing University of Chinese Medicine. Voucher specimens were deposited at the Herbarium of School of Chinese Materia Medica, Beijing University of Chinese Medicine.

Jatamana Valeriana Rhizome was homogenized to coarse powder $(8 \mathrm{~kg})$ and soaked in aqueous ethanol $(95 \%, 12 \mathrm{~L}$, $\mathrm{v} / \mathrm{v})$ three times at room temperature, and the combined alcoholic extract was filtered and evaporated under reduced pressure to yield a residue. The concentrated extract was then subjected to chromatographic separation on AB-8 macroporous adsorption resin with $70 \%, 80 \%$, and $90 \% \mathrm{EtOH}-$ $\mathrm{H}_{2} \mathrm{O}$ to give three fractions. Three fractions were subjected to chromatography on silica gel eluted with petroleum etherethyl acetate $(20: 1,10: 1,8: 1)$, then The fractions were combined based on the TLC analysis. We got ten compounds; the valtrate (Figure 1) was an oily matter identified by spectroscopic methods (UV, IR, ESI-MS, ${ }^{1} \mathrm{H}$ NMR, and ${ }^{13} \mathrm{C}$ NMR). The purity of valtrate was determined by HPLC analysis, which was identified by comparing with a standard specimen (National Institute for the Control of Pharmaceutical and Biological Products, Beijing, China). The sample was chromatographed under the following chromatographic conditions: Chromatographic column: Agilent Extend C18 column, $5 \mu \mathrm{m}, 250 \times 4.6 \mathrm{~mm}$; Mobile phase: gradient elution by acetonitrile-distilled water $(68 \%-32 \%)$; Flow rate: $1 \mathrm{~mL} / \mathrm{min}$; Column temperature: $30^{\circ} \mathrm{C}$ with UV detection at $254 \mathrm{~nm}$.

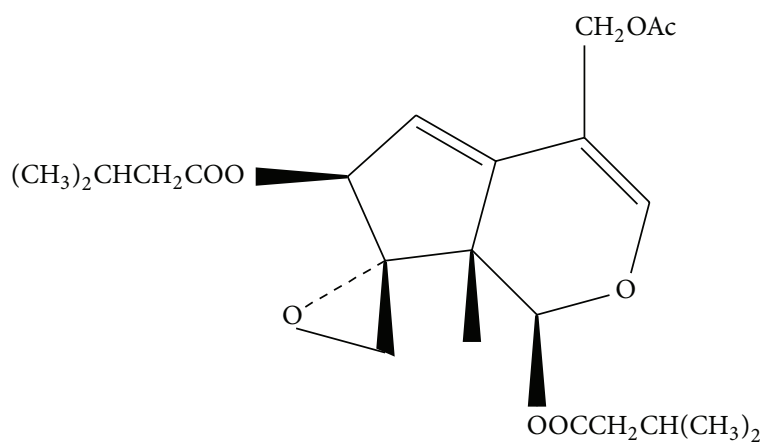

FIGURE 1: Structure of valtrate.

2.3. Drugs and Treatment. Diazepam was obtained from Yimin Pharmaceutical Factory of Beijing. All drugs were prepared immediately before use and were given orally in a volume of $1 \mathrm{~mL} / 100 \mathrm{~g}$ body weight for 10 days. diazepam at the dose of $1 \mathrm{mg} / \mathrm{kg}$ [18] was chosen as a positive control drug. Diazepam and valtrate were both dissolved in $0.5 \%$ Tween- 80 solution. For vehicle group, distilled water which contained $0.5 \%$ Tween- 80 was administered at the same volume. In this study, the rats were administered valtrate or diazepam 60 and 30 min before the test, respectively. The Elisa kit was obtained from R\&D. All experiments were carried out in quiet room under dim red light between 8:00 a.m. and 14:00 p.m. on the 10 th day of treatment.

2.4. Open Field Test. The OFT apparatus was a $180 \mathrm{~cm}$ diameter cylinder with $60 \mathrm{~cm}$ high walls. The center of the bottom of the apparatus had a $52 \mathrm{~cm}$ diameter section. As previously described [19], all rats were acclimatized to the test room for $1 \mathrm{~h}$. The rats were placed into the field at the same point against the wall and allowed to freely explore the apparatus for $10 \mathrm{~min}$. The total path length, the number of central entries, and the time spent in the center were recorded by an automatic video tracking system. OFT was performed $60 \mathrm{~min}$ after the final treatment of valtrate and $30 \mathrm{~min}$ after the diazepam. After each trial, the apparatus was wiped clean with a $10 \%$ ethanol solution.

2.5. Elevated Plus Maze. Immediately after the OFT, anxiolytic activity was measured using the EPM, which was consisted of two open arms $(50.8 \mathrm{~cm} \times 10.2 \mathrm{~cm} \times 1.3 \mathrm{~cm})$ and two closed arms $(50.8 \mathrm{~cm} \times 10.2 \mathrm{~cm} \times 40.6 \mathrm{~cm})$ that extended from a central platform $(10.2 \mathrm{~cm} \times 10.2 \mathrm{~cm})$. The maze was elevated to a height of $72.4 \mathrm{~cm}$ above the floor. The entire maze was constructed of clear Plexiglas [20]. Each rat was placed on the central square facing an open arm and allowed to freely explore the maze for $5 \mathrm{~min}$. Arm entries were defined as the entry of all four paws into an arm. A computer recorded the time spent on and number of entries into the open and closed arms by means of infrared photocells. The apparatus was wiped clean with a $30 \%$ ethanol solution and dried after each subject.

2.6. Determination of Serum Corticosterone. $10 \mathrm{~min}$ after the completion of the two behavioral tests, the rats were sacrificed 


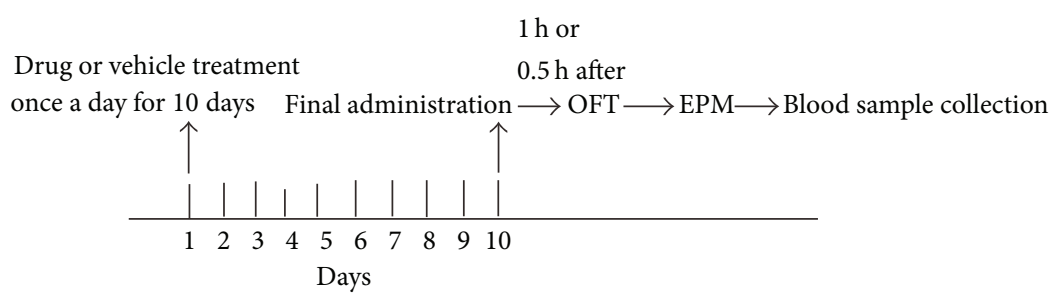

Figure 2: Experimental schedule. Experimental schedule, described in Material and Methods section, involved the OFT, EPM test, and the collection of blood sample.

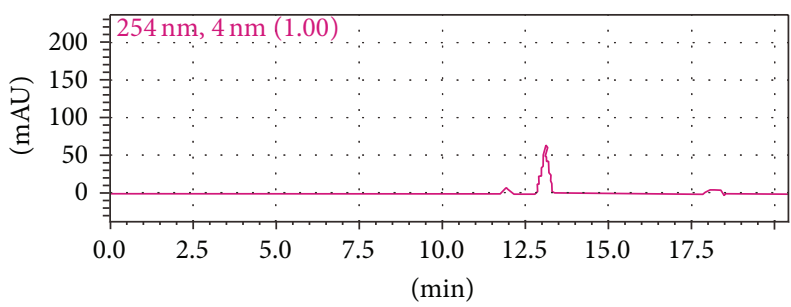

(a)

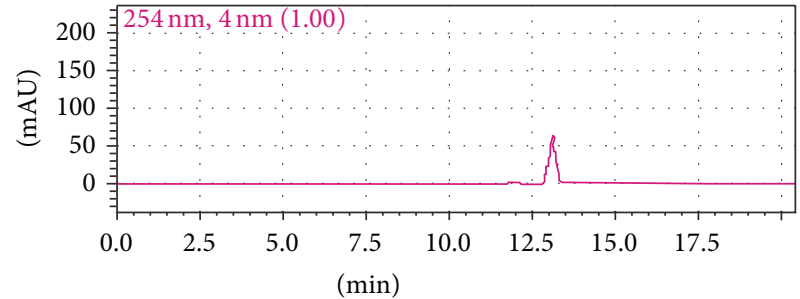

(b)

Figure 3: HPLC profile of valtrate using acetonitrile-distilled water (68\%-32\%) at $1 \mathrm{~mL} / \mathrm{min}$ on a Agilent Extend C18 column, $5 \mu \mathrm{m}$, $250 \times$ $4.6 \mathrm{~mm}, 30^{\circ} \mathrm{C}$ with UV detection at $254 \mathrm{~nm}$. (a) The sample of valtrate. (b) The standard specimen of valtrate.

by decapitation; then trunk blood was collected among the five groups to avoid any substantial time lag in samples collection. Samples were centrifuged at $3000 \mathrm{r} \cdot \mathrm{min}^{-1}$ for $15 \mathrm{~min}$ at $4^{\circ} \mathrm{C}$ and supernatants were stored at $-20^{\circ} \mathrm{C}$ until analysis. The content of corticosterone was determined by a commercially available enzyme-linked immunosorbent assay (ELISA) kit according to the manufacturer's instructions. The absorbance of each sample was measured at a wavelength of $450 \mathrm{~nm}$ and the results are presented as $\mathrm{ng} / \mathrm{mL}$. All procedures of the experiment were shown in Figure 2.

2.7. Statistical Analysis. The data were expressed as mean \pm SEM. The statistical analysis was carried out by one-way analysis of variance (ANOVA) following Student-NewmanKeul's post-hoc test using Prism 5.0 (Graphpad Software, Inc). Probability values lower than 0.05 were considered statistically significant.

\section{Results}

3.1. Assaying of Valtrate by HPLC. The results suggest that the purity of product can reach $99 \%$ (see Figure 3).

3.2. Effects of Valtrate on Open Field Test in Rats. The results for the OFT are shown in Figure 4. Analyses demonstrated significant effects on number of center entries $(F(4,55)=3.541, P<0.05)$ and time spent in central area $(F(4,55)=3.127, P<0.05)$; further analyses showed that valtrate at dose of $10 \mathrm{mg} / \mathrm{kg}$ significantly increased the entries in central area $(P<0.05)$. Valtrate at the dose of $20 \mathrm{mg} / \mathrm{kg}$ did not significantly increase the entries in central area $(P>0.05)$. Diazepam significantly increased the number of center entries $(P<0.05)$ and the time spent in central area
$(P<0.05)$. All of the doses of valtrate did not significantly increase the time spent in central area $(P>0.05)$. No difference in total path length was observed among the five groups $(F(4,55)=1.207, P>0.05)$. Locus diagram of open field test of every group is shown in Figure 5.

3.3. Effects of Valtrate on Elevated Plus Maze in Rats. As shown in Table 1 and Figure 6, the ANOVA indicated significant effects on percentage of time spent on the open $\operatorname{arm}(F(4,55)=7.755, P<0.01)$ and open arm entries $(F(4,55)=6.054, P<0.01)$. Compared to vehicle group, valtrate at the dose of $10 \mathrm{mg} / \mathrm{kg}$ significantly increased the percentage of time spent in the open arms and entry percentage into the open arms in the elevated plus maze $(P<0.01$; $P<0.01)$, and valtrate at the dose of $20 \mathrm{mg} / \mathrm{kg}$ increased the percentage of time spent in the open arms of the maze $(P<$ $0.01)$ but did not increase percentage of open arm entries $(P>$ $0.05)$. Diazepam also significantly increased the percentage of time spent on open arms $(P<0.01)$ and percentage into the open arms $(P<0.05)$. No difference was observed in total arm entries among groups $(F(4,55)=1.042, P>0.05)$.

3.4. The Level of Serum Corticosterone. As seen in Figure 7, the data show that administration of valtrate at the dose of $10 \mathrm{mg} / \mathrm{kg}$ and $20 \mathrm{mg} / \mathrm{kg}$ dose reduced the corticosterone level $(P<0.01, P<0.05)$. Similarly, serum corticosterone levels of rats treated with diazepam were lower than those of the vehicle group $(P<0.01)$.

\section{Discussion}

The present study was performed to analyze the behavioral effects of anxiolytic valtrate isolated from Valeriana jatamansi Jones, using two behavioural measurements of 


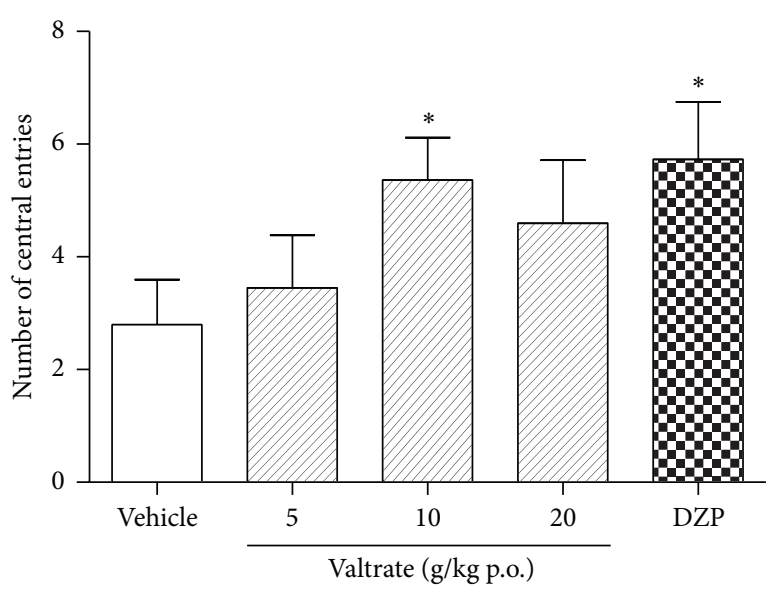

(a)

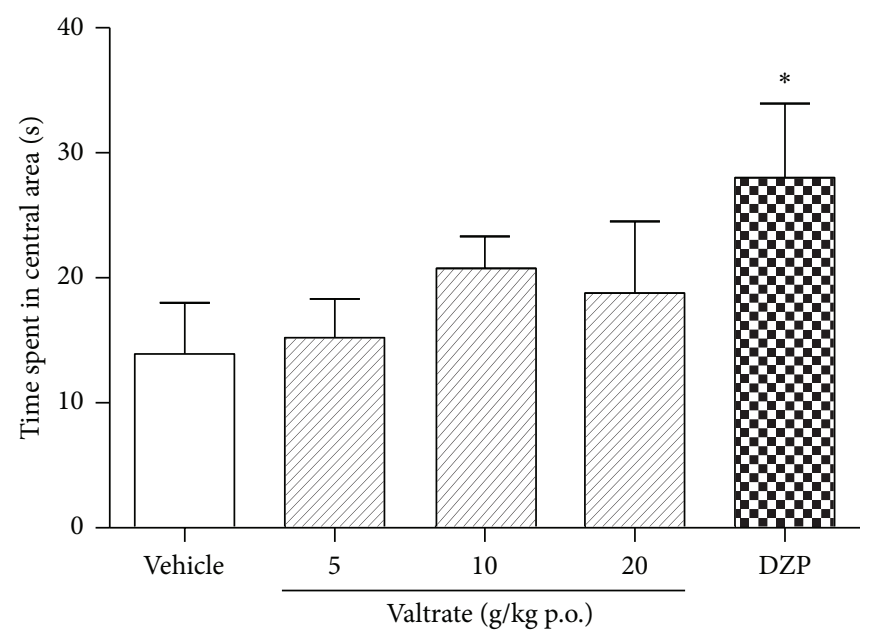

(b)

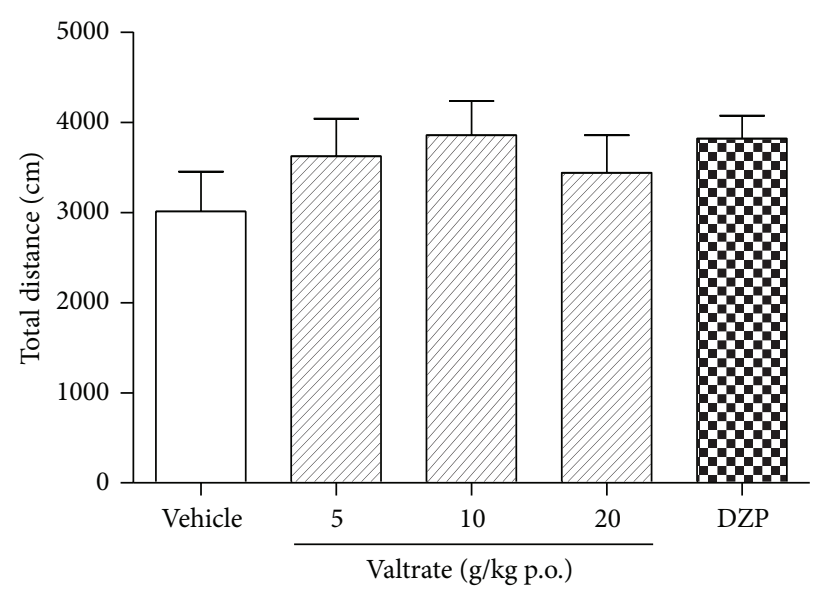

(c)

FIGURE 4: Effect of valtrate on the behavior of rat in the OFT in a 10 min session in the open field performed $1 \mathrm{~h}$ after the administration of vehicle (p.o.), valtrate $(5,10$, and $20 \mathrm{mg} / \mathrm{kg}$, p.o.), and $0.5 \mathrm{~h}$ after the administration of diazepam ( $1 \mathrm{mg} / \mathrm{kg}$, p.o.). (a) Number of central entries, (b) time spent in central area, and (c) total distance. Columns represent the means \pm SEM, $n=12$ rats. ${ }^{*} P<0.05$ compared to the vehicle group.

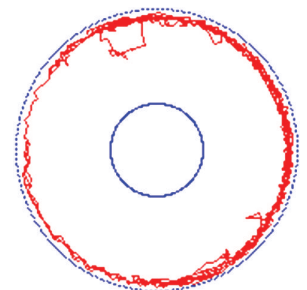

(a)

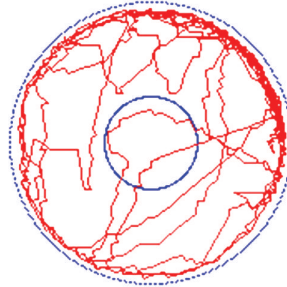

(b)

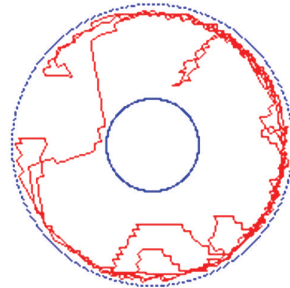

(c)

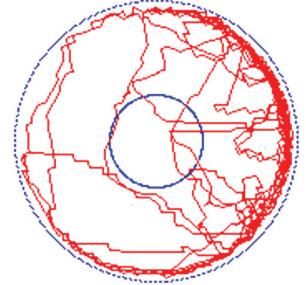

(d)

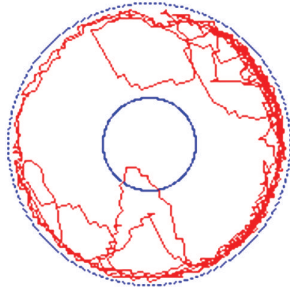

(e)

Figure 5: Locus diagram of OFT. (a) Vehicle, (b) DZP, and (c) Valtrate $5 \mathrm{mg} / \mathrm{kg}$, (d) valtrate $10 \mathrm{mg} / \mathrm{kg}$, and (e) valtrate $20 \mathrm{mg} / \mathrm{kg}$.

TABLE 1: Effect of diazepam and valtrate on the behavior of rats in the elevated plus-maze test.

\begin{tabular}{lcccccc}
\hline Group & Dose $(\mathrm{mg} / \mathrm{kg})$ & Open arm entries & Closed arm entries & Total arm entries & Time in open arms (s) & Time in closed arms (s) \\
\hline Vehicle & - & $3.07 \pm 0.59$ & $9.16 \pm 0.95$ & $10.07 \pm 1.45$ & $48.41 \pm 4.36$ & $189.94 \pm 10.57$ \\
Diazepam & 1 & $4.80 \pm 0.73$ & $9.70 \pm 0.76$ & $12.20 \pm 0.97$ & $98.92 \pm 10.07$ & $138.55 \pm 9.54$ \\
Valtrate & 5 & $2.00 \pm 0.29$ & $10.71 \pm 0.97$ & $9.50 \pm 1.59$ & $52.21 \pm 8.09$ & $183.31 \pm 15.45$ \\
& 10 & $6.36 \pm 1.16$ & $10.55 \pm 1.23$ & $13.33 \pm 1.41$ & $87.20 \pm 10.20$ & $143.13 \pm 8.92$ \\
& 20 & $4.22 \pm 0.47$ & $8.78 \pm 0.70$ & $11.75 \pm 1.11$ & $82.01 \pm 8.69$ & $147.51 \pm 8.68$ \\
\hline
\end{tabular}




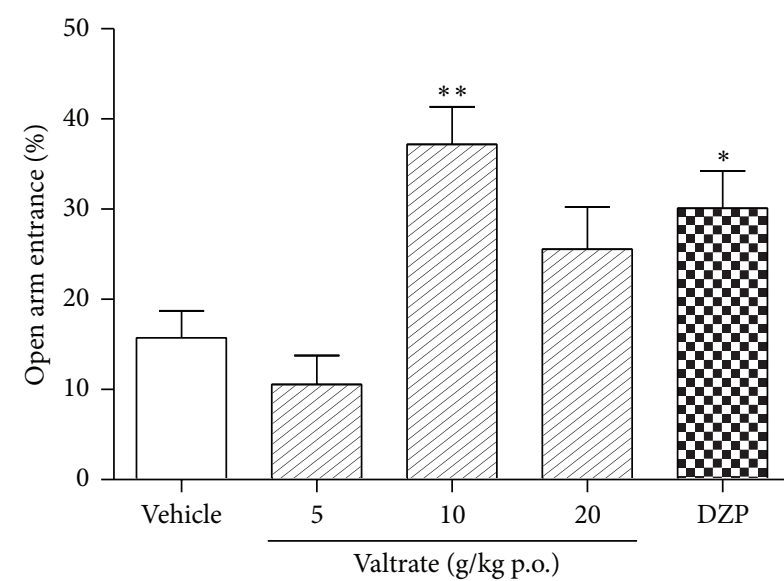

(a)

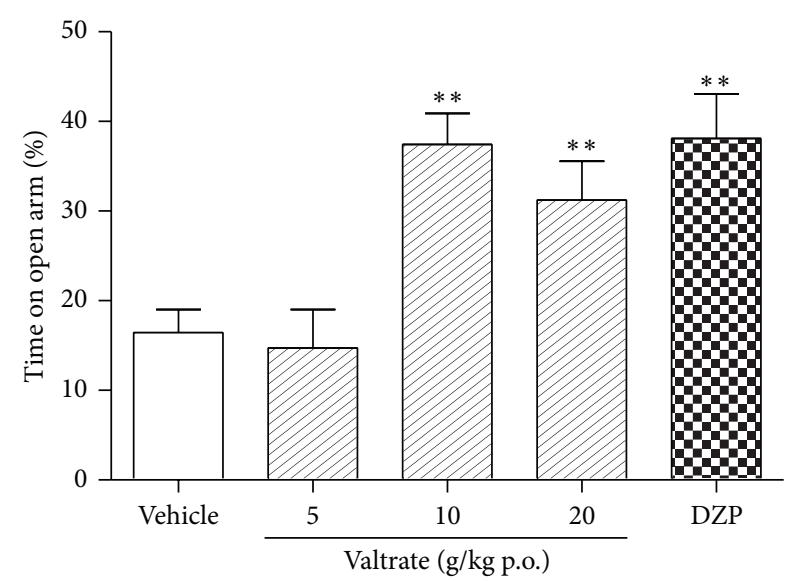

(b)

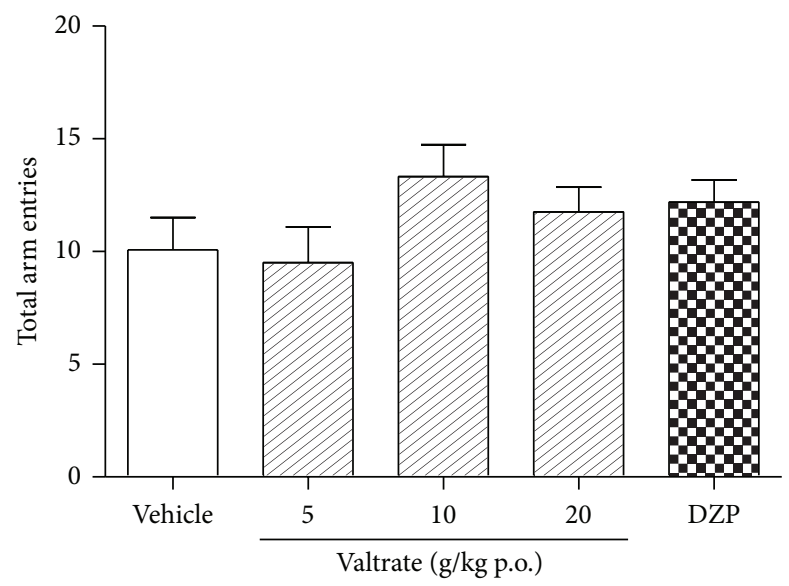

(c)

FIGURE 6: Behavioural performance of rat registered in a 5 min session in the EPM performed $1 \mathrm{~h}$ after the administration of vehicle (p.o.), valtrate $(5,10$, and $20 \mathrm{mg} / \mathrm{kg}$, p.o.), and $0.5 \mathrm{~h}$ after the administration of diazepam ( $1 \mathrm{mg} / \mathrm{kg}$, p.o.). (a) Percentage of number of entries into the open arm, (b) percentage of time spent into the open arms, and (c) total arm entries. Columns represent the means \pm SEM, $n=12$ rats. ${ }^{*} P<0.05,{ }^{* *} P<0.01$ compared to the vehicle group.

anxiety, OFT, and EPM. The results showed that valtrate exhibited anxiolytic-like activity and did not induce sedative side effects. We also found that valtrate could attenuate HPA axis activity by reducing the corticosterone level.

Valtrate was successfully isolated from subterranean parts of subterranean parts of various Valeriana species for the first time by Thies [21]. Our laboratory developed a high efficiency and practicality method for purifying Valtrate from Valeriana jatamansi Jones with AB-8 macroporous adsorption resin. The resin yielded the best efficiency when the concentration of the extraction was $3.5 \mathrm{mg} / \mathrm{mL}$, the $70 \%$ ethanol acted as the eluant, and the eluting speed was two column volumes per hour. AB-8 macroporous adsorption resin significantly increased the purity of valtrate (99\%), with advantage of high absorption, high elution rate, and low expense.

Hall originally described the OFT for the study of emotionality in rats [22], which is one of the most popular procedures in animal psychology and has been widely used to assess anxiety, emotionality, or responses to stress in animals $[23,24]$; the test is based on the rodents' natural tendency to stay near the perimeters of a novel environment and the aversion of rodents for open and illuminated spaces. The number of central entries or the time spent in the center area served as indices of anxiety and the distance was considered an index of locomotor activity $[25,26]$. Rats treated with valtrate at the dose of $10 \mathrm{mg} / \mathrm{kg}$ significantly increased the number of center entries and the total distance was not significantly affected. Therefore, valtrate $(10 \mathrm{mg} / \mathrm{kg})$ has a significant anxiolytic-like effect in this paradigm.

To further strength these data, we tested the anxiolyticlike effects of these treatments in EPM, Which is a classical animal analog for anxiolytic drugs and can play a key role in the screening of anxiolytic drugs on the central nervous system currently $[27,28]$. Normally, rodents tend to avoid open areas of the maze and a preference for sections enclosed by protective walls. Anxiolytic drugs shift the behavioral response toward exploration of the open arms [29]. The percentage entries into the open arms and time spent in the open arms are generally used as indices of anxiety and drugs increasing these measures show anxiolytic properties. 


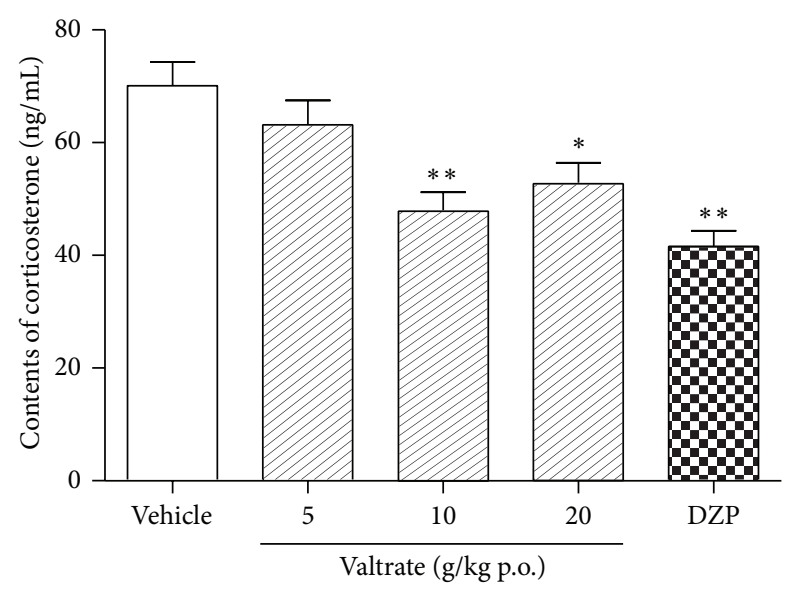

FIgURE 7: Effects of bergamot valtrate (5, 10, and $20 \mathrm{mg} / \mathrm{kg}$, p.o.) and diazepam ( $1 \mathrm{mg} / \mathrm{kg}$, p.o.) compared with vehicle groups on serum corticosterone after the behavior test. Columns represent the means \pm SEM, $n=12 .{ }^{*} P<0.05,{ }^{* *} P<0.01$ compared to the vehicle group.

The number of entries into the total arms was considered an index of locomotor activity. In the present study, the rats were treated with the higher doses of valtrate $(10 \mathrm{mg} / \mathrm{kg}$ and $20 \mathrm{mg} / \mathrm{kg}$ ) for 10 days, and anxiety-like behavior in the EPM was significantly attenuated, without altering the number of total arm entries, suggesting that valtrate induces specific anxiolytic-like effects.

The alcohol extract from Valeriana jatamansi Jones (0.3, $0.6,0.9 \mathrm{~g} / \mathrm{kg}$ ) could increase the open entries percent and open time percent in the EPM [30]. As the content of valtrate in alcohol extract from Valeriana jatamansi Jones is about $2.87 \%, 5 \mathrm{mg} / \mathrm{mL}$ valtrate in rat is equivalent to $0.3 \mathrm{~g} / \mathrm{mL}$ alcohol extract of Valeriana jatamansi Jones in mice in terms of equal valtrate efficacy. Thus, the doses of valtrate $(5,10$, and $20 \mathrm{mg} / \mathrm{kg}$ ) were chosen in this study. We also performed an acute experiment to study the anxiolytic effect of valtrate, and valtrate did not affect the behavior tests in EPM and OFT (data not shown). Therefore, the valtrate was administered with ten days. Diazepam is a classical drug to treat anxiety and was chosen as a positive drug in this study. As expected, diazepam had a significant anxiolytic-like effect in both EPM and OFT. The anxiolytic effect of the valtrate $(10 \mathrm{mg} / \mathrm{kg})$ was almost equivalent to that of diazepam $(1 \mathrm{mg} / \mathrm{kg})$ in EPM and the number of central entries in OFT. Although valtrate did not increase the time spent on the center of the open field compared to the vehicle group, there were marginal significant differences between the valtrate and the vehicle group on these tests. In addition, both valtrate $(10 \mathrm{mg} / \mathrm{kg})$ and diazepam $(1 \mathrm{mg} / \mathrm{kg})$ could reduce the corticosterone levels after behavior tests. Therefore, we thought that the anxiolytic effect of valtrate $(10 \mathrm{mg} / \mathrm{kg})$ was almost equivalent to diazepam $(1 \mathrm{mg} / \mathrm{kg})$.

The drugs (valtrate or diazepam) in this study were administered 60 and $30 \mathrm{~min}$ before the test; there should be a control group for each drug treatment. We compared these two vehicle groups (administrated $30 \mathrm{~min}$ and $60 \mathrm{~min}$, resp.).
The rats of these groups were exposed to the same procedure. The results suggested that there was no difference between the two groups (data not shown). To avoid too much groups in the present study, one vehicle group (60 min before test) was used as control.

It should be noted that the intermediate dose of valtrate was the most effective in decreasing anxiety-like behavior tests and corticosterone concentrations. One possible reason may be that the highest dose of valtrate or its metabolites may act as an inducer for hepatic microsomal enzyme, which can increase metabolism of the drug and result in reducing curative effect. In addition, valtrate $(10 \mathrm{mg} / \mathrm{kg}$ and $20 \mathrm{mg} / \mathrm{kg})$ was able to decrease corticosterone concentration $(P<0.01$ and $P<0.05$, resp.), but this effect was not observed in the behavior tests. Although valtrate at the dose of $20 \mathrm{mg} / \mathrm{kg}$ did not increase percentage of open arm entries $(P=0.052)$ and the number of central entries $(P=0.058)$, there were marginal significant differences between the valtrate $(20 \mathrm{mg} / \mathrm{kg})$ and the vehicle group on these two tests. Moreover, individual differences among rats in the highest dose valtrate $(20 \mathrm{mg} / \mathrm{kg})$ group are larger than these in intermediate dose valtrate $(10 \mathrm{mg} / \mathrm{kg})$ group. The same situation was observed in the open field test. However, valtrate at the dose of $10 \mathrm{mg} / \mathrm{kg}$ and $20 \mathrm{mg} / \mathrm{kg}$ did not increase the time spent on the center of the open field compared to the vehicle group $(P=0.057$ and $P=0.063$, resp.). There were marginal significant differences between the valtrate group $(10 \mathrm{mg} / \mathrm{kg}$ or $20 \mathrm{mg} / \mathrm{kg}$ ) and the vehicle group in the time spent in the center area.

Neuroendocrine system plays a key role in the stability of the body environment. Hormones change these neurons' network by making change in information and altering the neurotransmitter between cells in cell level, thus affecting the central nervous system function [31]. It is well known that hypothalamic-pituitary-adrenocortical (HPA) axis activation is a key component of the physiological response to stress and anxiety. The HPA axis is activated by stress; then corticosterone is released from the adrenal gland. The stress hormone corticosterone was measured to investigate the response of the HPA axis to valtrate. Research suggests that the exposure of rodents to the standard elevated plus maze activates the HPA axis, leading to an enhancement of plasma corticosterone [32]. In addition, there was a peak in corticosterone secretion which occurs 5 to $10 \mathrm{~min}$ after exposure to two different anxiety/fear tests [33]. It has been reported that Valeriana jatamansi Jones extract played a role in antianxiety via regulation of the HPA axis [30]. In the present study, as the stress hormone corticosterone was measured as the rats were subjected to both EPM and OF tests. These two tests were performed in two adjacent rooms, the delay time was less than one minute, and we thought that these procedures might not influence the effectiveness of the drug or plasma corticosterone concentrations, which were also used by other researchers [34,35]. Our data showed that valtrate $(10 \mathrm{mg} / \mathrm{kg})$, a dose which produced anxiolytic activity in the behavioural experiments, attenuated the activity of HPA axis by reducing the corticosterone response to the stress of exposure to the elevated plus maze. These findings indicate that the decreased anxiety-related behaviours may be related to the attenuation of HPA axis activity. 
You et al. had reported the anxiolytic-like effects of compound Valeriana jatamansi Jones in mice [36]. Compound Valeriana jatamansi Jones is composed of Valerianae Jatamansi Rhizoma et Radix, Ziziphi Spinosae Semen, and Albiziae Cortex and Junci Medulla (in a ratio of 12:9:9:1). They reported that the compound Valerianae Jatamansi Jone has anxiolytic effects but no sedative effect at dose of 2.4 and $4.8 \mathrm{~g} / \mathrm{kg}$. As the content of valtrate in Valeriana jatamansi Jones is about $1.8 \%, 2.4 \mathrm{~g}$ and $4.8 \mathrm{~g}$ valtrate compound might contain valtrate $16.74 \mathrm{mg}$ and $33.48 \mathrm{mg}$, respectively. In our study, valtrate at the dose of $10 \mathrm{mg} / \mathrm{kg}$ and $20 \mathrm{mg} / \mathrm{kg}$ has anxiolytic-like effect in rats. Thus, valtrate might be the main component to possess the anxiolytic-like effect of compound Valeriana jatamansi Jones. However, it is very interesting to contrast some pharmacological property of valtrate and Valeriana jatamansi Jones (or compound Valeriana jatamansi Jones) on behavior and plasma corticosterone. In addition, we did not measure the corticosterone levels in treated nonstressed rats. As the present procedure is characterized by two factors (stress and treatment), the corticosterone levels in treated nonstressed rats could strongly improve our present results and will be added in the future study.

The EPM test is considered one of the most widely validated tests for assaying new benzodiazepine-like anxiolytic agents [37]. GABA is the most important inhibitory neurotransmitter in the human central nervous system. Most of GABA receptors have separate modulatory sites sensitive to benzodiazepines. It is well known that the GABA mediated inhibition of the HPA axis at the level of the paraventricular nucleus of the hypothalamus [38]. As a consequence, we hypothesized that the decreased corticosterone levels by valtrate may also be related to the GABAergic neurotransmission.

\section{Conclusions}

In conclusion, the present study indicates that valtrate exhibits anxiolytic-like profiles in the elevated plus maze test and the open field test. Valtrate also attenuated HPA axis activity by reducing the corticosterone level.

\section{Conflict of Interests}

No conflict of financial interests exists.

\section{Acknowledgment}

This work was supported by the Key New Drugs Innovation project from Ministry of Science and Technology (2012ZX09102201-018) and National Science Foundation of China (30800301, 31170992, 31371038).

\section{References}

[1] E. H. Reynolds, "Brain and mind: a challenge for WHO," The Lancet, vol. 361, no. 9373, pp. 1924-1925, 2003.

[2] J. H. Woods, J. L. Katz, and G. Winger, "Benzodiazepines: use, abuse, and consequences," Pharmacological Reviews, vol. 44, no. 2, pp. 155-338, 1992.
[3] S. Paterniti, C. Dufouil, and A. Alpérovitch, "Long-term benzodiazepine use and cognitive decline in the elderly: the epidemiology of vascular aging study," Journal of Clinical Psychopharmacology, vol. 22, no. 3, pp. 285-293, 2002.

[4] L. N. Ravindran and M. B. Stein, "The pharmacologic treatment of anxiety disorders: a review of progress," The Journal of Clinical Psychiatry, vol. 71, no. 7, pp. 839-854, 2010.

[5] J.-Y. Guo, C.-C. Han, and Y.-M. Liu, "A contemporary treatment approach to both diabetes and depression by cordyceps sinensis, Rich in Vanadium," Evidence-Based Complementary and Alternative Medicine, vol. 7, no. 3, pp. 387-389, 2010.

[6] H. Z. Zheng and J. L. Shi, "Anxiolytic-like effects of compound zhi zhu xiang Capsule about anxiety disorders of learning in clinical," Modern Journal of Integrated Traditional Chinese and Western Medicine, vol. 30, pp. 3395-3396, 2012.

[7] Z. Y. Yan, T. E. Zhang, J. Peng, Z. P. Zhang, J. Z. Qin, and C. Chen, "Effect of the extract of Valeriana jatamansi Jones on the ethology and neurotransm itter in the brain in the anxietymodel of rat," Pharmacology and Clinics of Chinese Materia Medica, vol. 24, pp. 67-69, 2008.

[8] S.-H. Li and Z.-Y. Yan, "Research of iridoids from Valeriana jatamansi Jones," Chinese Journal of New Drugs, vol. 21, no. 6, pp. 633-637, 2012.

[9] N. Fuzzati, J. L. Wolfender, K. Hostettmann, J. D. Msonthi, S. Mavi, and L. P. Molleyres, "Isolation of antifungal valepotriates from Valeriana capense and the search for valepotriates in crude Valerianaceae extracts," Phytochemical Analysis, vol. 7, no. 2, pp. 76-85, 1996.

[10] C. Keochanthala-Bounthanh, J. P. Beck, M. Haag-Berrurier, and R. Anton, "Effects of two monoterpene esters, valtrate and didrovaltrate, isolated from Valeriana wallichii, on the ultrastructure of hepatoma cells in culture," Phytotherapy Research, vol. 7, no. 2, pp. 124-127, 1993.

[11] C. Keochanthala-Bounthanh, M. Haag-Berrurier, J. P. Beck, and R. Ant on, "Effects of thiol compounds versus the cytotoxicity of valepotriates on cultured hepatoma cells," Planta Medica, vol. 56, no. 2, pp. 190-192, 1990.

[12] C. Bounthanh, C. Bergmann, J. P. Beck, M. Haag-Berrurier, and R. Anton, "Valepotriates, a new class of cytotoxic and antitumor agents," Planta Medica, vol. 41, no. 1, pp. 21-28, 1981.

[13] L. Chen, L. P. Kang, L. P. Qin, H. C. Zheng, and C. Guo, "The sedative activity of the Valepotriates in mice," Chinese Traditional Patent Medicine, vol. 25, no. 8, pp. 663-665, 2003.

[14] G. R. Dawson and M. D. Tricklebank, "Use of the elevated plus maze in the search for novel anxiolytic agents," Trends in Pharmacological Sciences, vol. 16, no. 2, pp. 33-36, 1995.

[15] M. J. Millan, "The neurobiology and control of anxious states," Progress in Neurobiology, vol. 70, no. 2, pp. 83-244, 2003.

[16] L. A. Brotto, A. M. Barr, and B. B. Gorzalka, "Sex differences in forced-swim and open-field test behaviours after chronic administration of melatonin," European Journal of Pharmacology, vol. 402, no. 1-2, pp. 87-93, 2000.

[17] C. Belzung and G. Griebel, "Measuring normal and pathological anxiety-like behaviour in mice: a review," Behavioural Brain Research, vol. 125, no. 1-2, pp. 141-149, 2001.

[18] Y. L. Wang, J. L. Shi, L. Yong, R. Zhao, Y. J. Zhai, and J. Y. Guo, "Anxiolytic-like effects of compound Zhi Zhu Xiang in rats," Evidence-Based Complementary and Alternative Medicine, vol. 2012, Article ID 701289, 7 pages, 2012.

[19] A. Polissidis, O. Chouliara, A. Galanopoulos et al., "Individual differences in the effects of cannabinoids on motor activity, dopaminergic activity and DARPP-32 phosphorylation 
in distinct regions of the brain," The International Journal of Neuropsychopharmacology, vol. 13, no. 9, pp. 1175-1191, 2010.

[20] R. G. Lister, "Ethologically-based animal models of anxiety disorders," Pharmacology and Therapeutics, vol. 46, no. 3, pp. 321-340, 1990.

[21] P. W. Thies, "Die konstitution der valepotriate. Mitteilung über die wirkstoffe des baldrians," Tetrahedron, vol. 24, no. 1, pp. 313347, 1968.

[22] R. N. Walsh and R. A. Cummins, "The open-field test: a critical review," Psychological Bulletin, vol. 83, no. 3, pp. 482-504, 1976.

[23] F. Sherif, J. Harro, A. El-Hwuegi, and L. Oreland, "Anxiolyticlike effect of the GABA-transaminase inhibitor vigabatrin (gamma-vinyl GABA) on rat exploratory activity," Pharmacology Biochemistry and Behavior, vol. 49, no. 4, pp. 801-805, 1994.

[24] H. H. Ang and H. S. Cheang, "Studies on the anxiolytic activity of Eurycoma longifolia Jack roots in mice," Japanese Journal of Pharmacology, vol. 79, no. 4, pp. 497-500, 1999.

[25] L. Prut and C. Belzung, "The open field as a paradigm to measure the effects of drugs on anxiety-like behaviors: a review," European Journal of Pharmacology, vol. 463, no. 1-3, pp. 3-33, 2003.

[26] G. Rentesi, K. Antoniou, M. Marselos, A. Fotopoulos, J. Alboycharali, and M. Konstandi, "Long-term consequences of early maternal deprivation in serotonergic activity and HPA function in adult rat," Neuroscience Letters, vol. 480, no. 1, pp. 7-11, 2010.

[27] S. K. Bhattacharya and S. K. Mitra, "Anxiolytic activity of Panax ginseng roots: an experimental study," Journal of Ethnopharmacology, vol. 34, no. 1, pp. 87-92, 1991.

[28] R. U. Hasenöhrl, C. Nichau, C. Frisch et al., "Anxiolytic-like effect of combined extracts of Zingiber officinale and ginkgo biloba in the elevated plus-maze," Pharmacology Biochemistry and Behavior, vol. 53, no. 2, pp. 271-275, 1996.

[29] J.-Y. Guo, C.-Y. Li, Y.-P. Ruan et al., "Chronic treatment with celecoxib reverses chronic unpredictable stress-induced depressive-like behavior via reducing cyclooxygenase- 2 expression in rat brain," European Journal of Pharmacology, vol. 612, no. 1-3, pp. 54-60, 2009.

[30] Z. Y. Yan, T. E. Zhang, T. Xiao et al., "Anti-anxiety effect of Valeriana jatamansi Jones extract via regulation of hypothalamuspituitary-adrenal axies," Neural Regeneration Research, vol. 14, pp. 1071-1075, 2010.

[31] H. Basedovsky and E. Sorkin, "Network of immune neuroendocrine interactions," Clinical \& Experimental Immunology, vol. 27, no. 1, pp. 1-22, 1977.

[32] R. J. Rodgers, J. Haller, A. Holmes, J. Halasz, T. J. Walton, and P. F. Brain, "Corticosterone response to the plus-maze: high correlation with risk assessment in rats and mice," Physiology and Behavior, vol. 68, no. 1-2, pp. 47-53, 1999.

[33] V. C. S. Amaral, K. Santos Gomes, and R. L. Nunes-de-Souza, "Increased corticosterone levels in mice subjected to the rat exposure test," Hormones and Behavior, vol. 57, no. 2, pp. 128$133,2010$.

[34] E. T. Venâncio, N. F. M. Rocha, E. R. V. Rios et al., "Anxiolyticlike effects of standardized extract of Justicia pectoralis (SEJP) in mice: involvement of GABA/benzodiazepine in receptor," Phytotherapy Research, vol. 25, no. 3, pp. 444-450, 2011.

[35] C. J. Miguel, F. R. L. Juan, L. R. P. Maria et al., "The aqueous crude extract of Montanoa frutescens produces anxiolytic-like effects similarly to diazepam in Wistar rats: involvement of GABAA receptor," Journal of Ethnopharmacology, vol. 143, no. 2, pp. 592-598, 2012.
[36] J. S. You, M. Peng, J. L. Shi et al., "Evaluation of anxiolytic activity of compound Valeriana jatamansi Jones in mice," BMC Complementary and Alternative Medicine, vol. 12, p. 223, 2012.

[37] S. Pellow, P. Chopin, S. E. File, and M. Briley, "Validation of open:closed arm entries in an elevated plus-maze as a measure of anxiety in the rat," Journal of Neuroscience Methods, vol. 14, no. 3, pp. 149-167, 1985.

[38] W. E. Cullinan, D. R. Ziegler, and J. P. Herman, "Functional role of local GABAergic influences on the HPA axis," Brain Structure and Function, vol. 213, no. 1-2, pp. 63-72, 2008. 


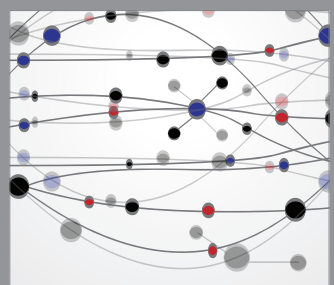

The Scientific World Journal
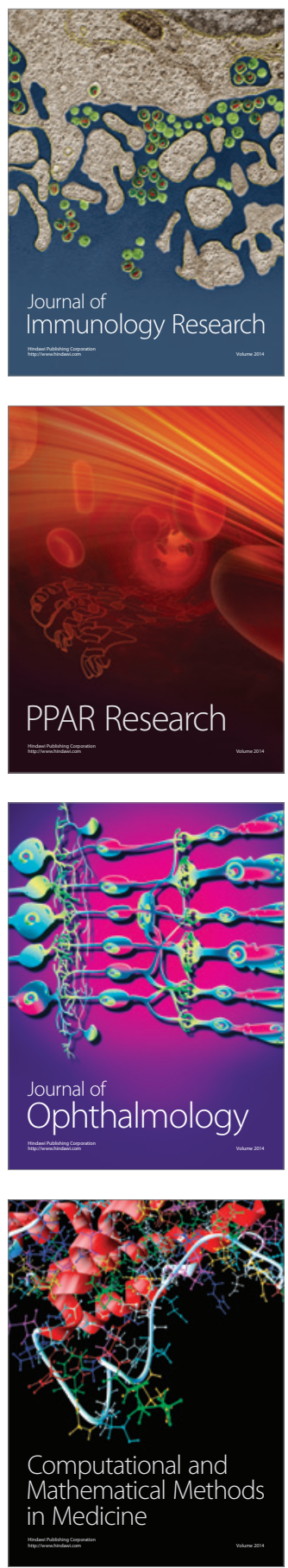

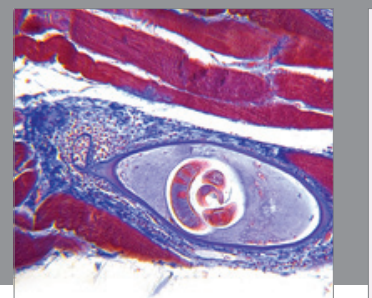

Gastroenterology

Research and Practice
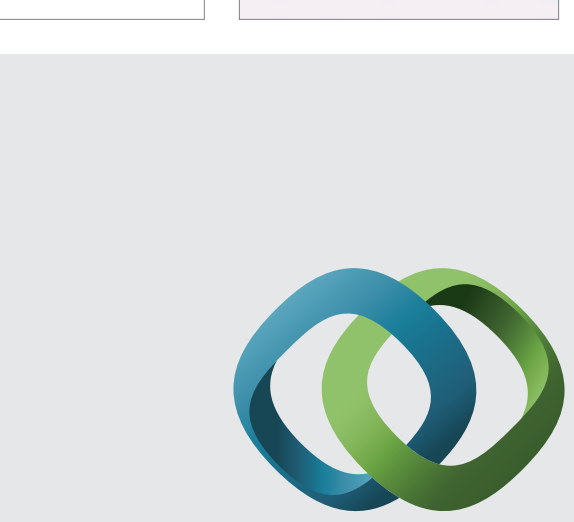

\section{Hindawi}

Submit your manuscripts at

http://www.hindawi.com
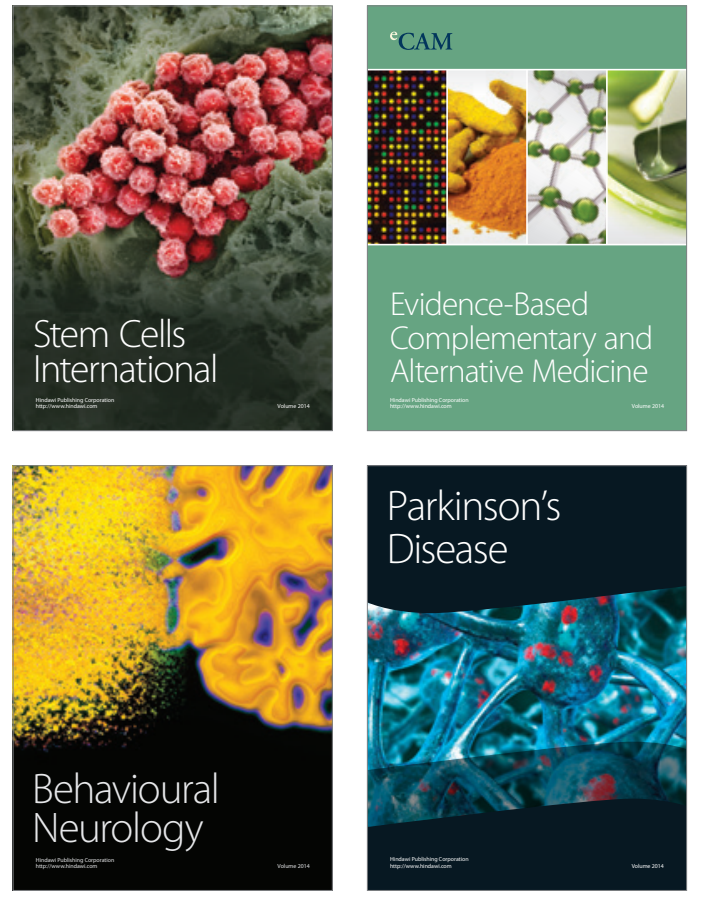
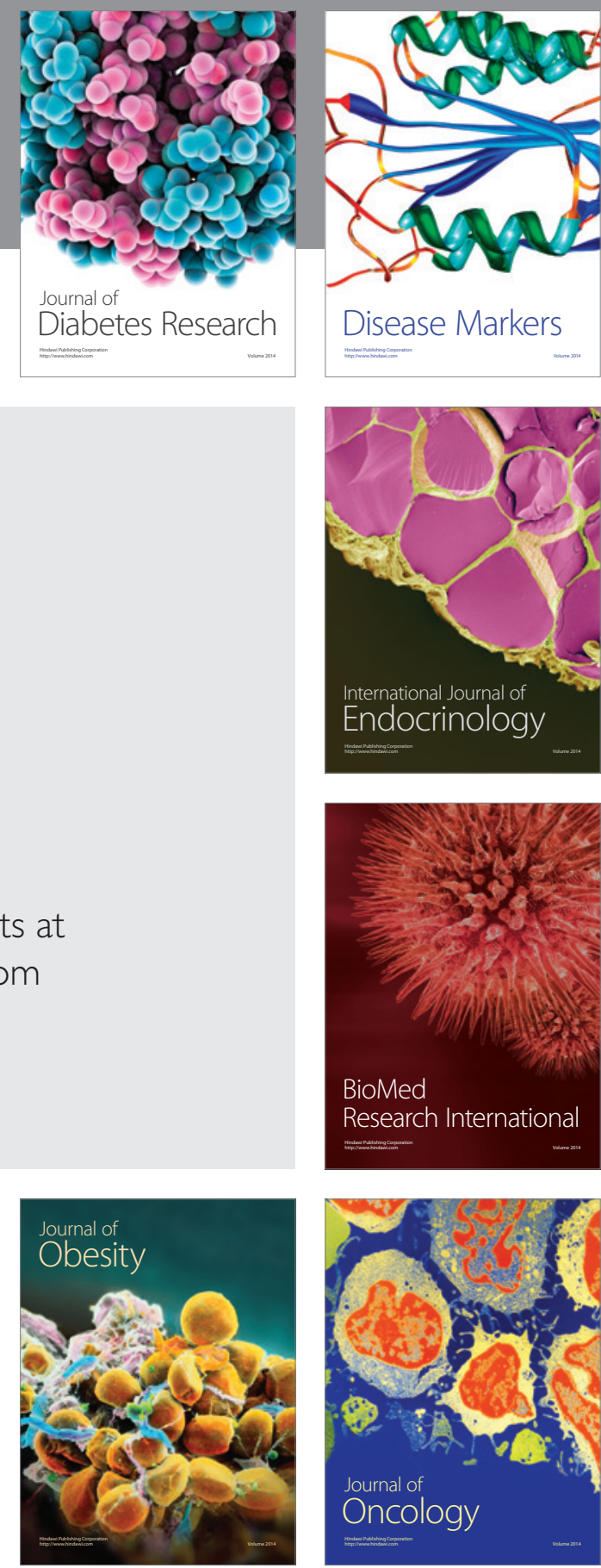

Disease Markers
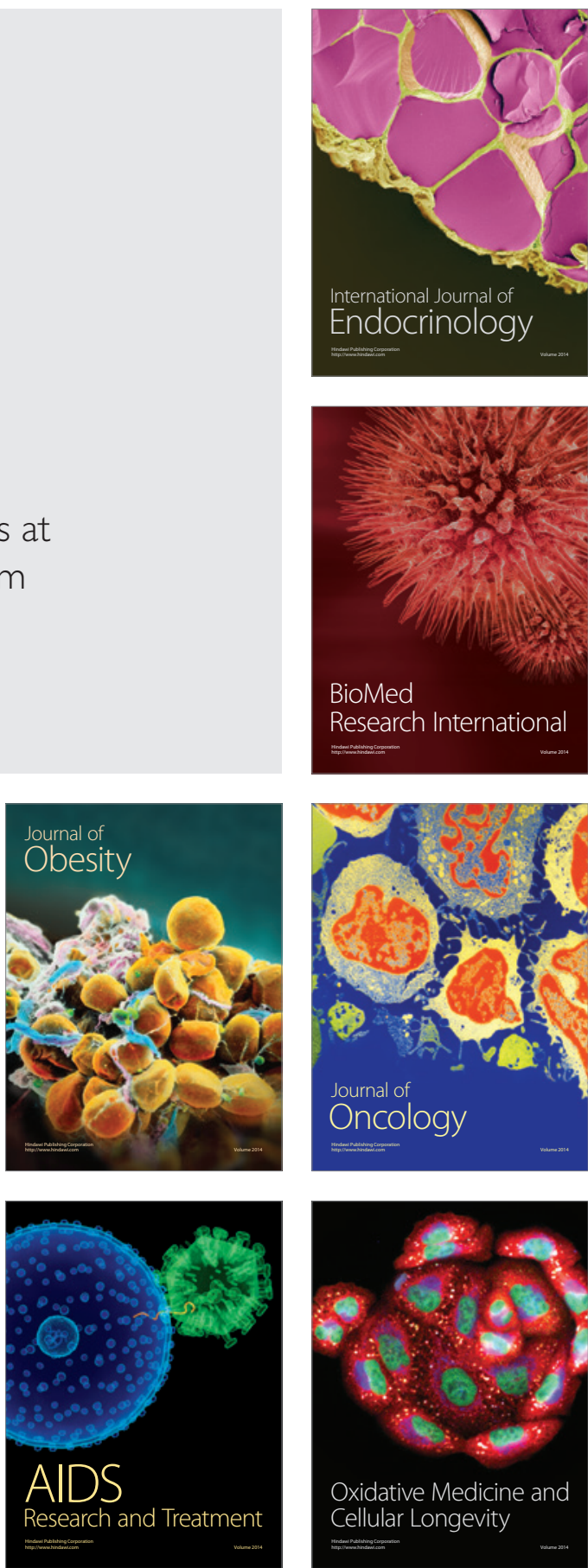